\title{
O Cuidado Empático: Contribuições para a Ética e Sua Interface com a Educação Moral na Formação em Saúde
}

\author{
Empathic Care: Contributions to Ethics and \\ its Interface with Moral Education in \\ Health Training
}

Marcelo de Almeida Mayernyik Fabio Alves Gomes de Oliveira II

PALAVRAS-CHAVE

- Ética;

- Empatia;

- Identidade de Gênero;

- Desenvolvimento Moral;

- Educação Superior;

- Cuidado Centrado no Paciente;

- Educação Médica.

KEYWORDS

- Ethics;

- Empathy;

- Gender Identity;

- Moral Development;

- Higher Education;

- Patient-Centered Care;

- Medical Education.
Recebido em: 12/07/2015

Reencaminhado em: 12/10/2015

Aprovado em: 11/11/2015

\section{RESUMO}

O presente artigo apresenta alguns pontos essenciais do pensamento do filósofo Michael Slote em sua obra "The ethics of care and empathy". Situamos a sua produção no contexto em que a ética do cuidado foi desenvolvida e problematizada, evidenciando, sobretudo, a questão de gênero que atravessa essa perspectiva ética. Assim, convocamos autores e autoras que dialogam estreitamente com as questões levantadas por Slote como interlocutores fundamentais para se pensar a empatia como componente fundamental da ética do cuidado. Em sequência, resgatamos o sentido ontológico do cuidado e da responsabilidade, correlacionando-os com a prática do cuidado em saúde. Ao final, apresentamos um caso paradigmático para um debate concreto da ética do cuidado e empatia no âmbito da educação moral, destacando sua importância no processo de formação dos profissionais de saúde no Brasil.

\begin{abstract}
This paper presents some key points from philosopher Michael Slote's thinking in his work "The Ethics of Care and Empathy". We therefore situate his production in the context where the ethics of care was developed and critically questioned, demonstrating primarily the issue of gender which crosses this ethical perspective. Thus, we call upon authors that hold a close dialogue with the issues raised by Slote, as fundamental interlocutors to think about empathy as a fundamental component of the ethics of care. In sequence, we rescued the ontological sense of care and responsibility correlating them with the practice of health care. Finally, we present a paradigmatic case for a concrete debate of the ethics of care and empathy in the context of moral education, highlighting its importance in the higher education process of health professionals in Brazil.
\end{abstract}

REVISTA BRASILEIRA DE EDUCAÇãO MÉDICA

11

$40(1): 11-20 ; 2016$
${ }^{I}$ Universidade Federal Fluminense, Niterói, RJ, Brasil.

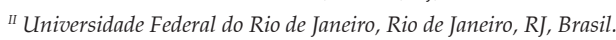




\section{INTRODUÇÃO}

A partir da edição do livro In a different voice: psychological theory and women's development, de Carol Gilligan ${ }^{1}$, em 1982, o debate sobre o cuidado ganha fôlego, instaurando um recorte de gênero importante, até então pouco ou nada expressivo na discussão moral sobre as concepções éticas vigentes.

Gilligan ${ }^{1}$, no desenvolvimento de sua teoria, vai além da denúncia da supervalorização do pensamento masculino no campo da filosofia e da ética que, ao longo de séculos, centrou a discussão da moralidade em torno de questões de justiça, regras e direitos, negligenciando o pensamento feminino. Assim, ela apresenta a ética do cuidado, essencialmente feminina, que valoriza as pessoas, as relações interpessoais, os desejos e as necessidades, podendo, em certa medida, complementar a ética de justiça.

O filósofo Michael Slote ${ }^{2}$, na obra The ethics of care and empathy, adota a abordagem teórica sobre o desenvolvimento moral de Gilligan ${ }^{1}$, ampliando a perspectiva de abrangência da ética do cuidado, ao afirmar que esta tem potencial para adquirir status de um projeto ético abrangente em relação à moralidade privada e pública, rompendo, assim, com o estigma entre gêneros.

Para Slote², a atitude ou motivação ética solidária na ética do cuidado deve ser orientada pela empatia, que é o principal mecanismo de cuidado, de benevolência e de compaixão.

A empatia é definida como "uma resposta afetiva mais adequada à situação do outro do que à própria situação"3 $(\mathrm{p}$. 4), a partir da inferência, apreensão e compreensão dos sentimentos do outro ${ }^{4}$ e de "como o outro, literalmente, percebe determinada situação"s (p. 166); no campo da saúde, é um elemento essencial para o processo terapêutico, pois permite que o profissional que produz o cuidado incorpore em sua própria experiência "uma compreensão exata, empática, da consciência do paciente [...] sentir seu mundo privado como se fosse o seu próprio, sem nunca perder o 'como se'. Esta qualidade é a empatia" $^{6}$ (p. 98) e, por esse motivo, a "empatia deve caracterizar todas as profissões de saúde ${ }^{\prime \prime 7}$ (p. 1100).

Isto posto, a proposta deste estudo é apresentar alguns pontos essenciais do pensamento de Slote ${ }^{2}$, bem como resgatar o sentido ontológico do cuidado $^{8}$ e sua relação intrínseca com a noção de responsabilidade $e^{9,10,11,12,13}$ e com o pacto de cuidados $^{14}$, indicando, por fim, como tais pensamentos podem contribuir, ou têm contribuído, para a educação moral na formação de profissionais da área de saúde.

\section{A ÉTICA DO CUIDADO}

As filosofias moral, social e política foram desenvolvidas sob a égide do pensamento masculino. Aristóteles ${ }^{15}$ (p. 55) afirmava que as mulheres, assim como os escravos, eram menos racionais que os homens e, portanto, deveriam ser governadas por eles: "é dessas duas associações, entre o homem e a mulher, e o senhor e o escravo, que se forma inicialmente a família". $\operatorname{Kant}^{16}$ (p. 157) também defendia o governo das mulheres pelos homens, enfatizando que para as mulheres "falta personalidade civil, e suas existências são, por assim dizer, tão-só inerências". Neste mesmo eixo argumentativo, Freud ${ }^{17}$ (p. 298) declarou que a mulher "mostra menos senso de justiça que o homem, menor inclinação a submeter-se às grandes exigências da vida, que é mais frequentemente guiada por sentimentos afetuosos e hostis ao tomar decisões". Nesses exemplos, observa-se que a construção do pensamento filosófico adotou como premissa a supremacia do homem perante a mulher, ou seja, os homens, por serem considerados titulares naturais de uma racionalidade superior, acabaram por destituir as mulheres de "voz na vida pública"18 (p. 227).

Essa dominação masculina, do modo como é imposta e vivenciada, foi denominada por Bourdieu ${ }^{19}$ de "violência simbólica"19 (p. 12), que corresponde a uma "violência suave, insensível, invisível a suas próprias vítimas, que se exerce essencialmente pelas vias puramente simbólicas da comunicação e do conhecimento"19 (p. 12)

Nesse contexto, da supremacia do modo de pensar masculino frente ao modo de pensar feminino, Kohlberg ${ }^{20}$ acompanhou e observou, desde o final da década de 1950, o desenvolvimento moral de meninos e meninas durante um período de 20 anos, o que o levou a categorizar seis estágios de desenvolvimento do raciocínio moral: orientação para a "obediên-

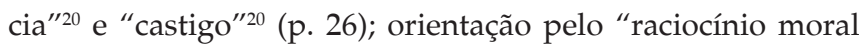
egocêntrico" ${ }^{20}$ (p. 26); orientação para "cumprir com aquilo que as pessoas esperam, como ser um bom filho, um bom amigo ou um bom marido" ${ }^{20}$ (p. 26); orientação de "manutenção da ordem social" ${ }^{20}$ (p. 26); orientação pelo "contrato social e os direitos individuais" 20 (p. 26); e, por fim, a orientação "pelos princípios éticos universais" ${ }^{\prime 20}$ (p. 26).

Pela escala de Kohlberg ${ }^{20}$, as mulheres chegam a atingir o estágio três, em que a moralidade é concebida pelas relações interpessoais, "caracteriza-se pela necessidade de cumprir com aquilo que as pessoas esperam [...] há uma consciência inicial de que os interesses coletivos são mais importantes do que os individuais" ${ }^{\prime 20}$ (p. 26); já os homens podem atingir os estágios mais elevados do desenvolvimento moral que figuram as regras e os princípios universais de justiça; logo, segundo essa teoria, as mulheres são "deficientes no desenvolvimento moral" ${ }^{\prime \prime}$ (p. 18). Esse aparente déficit do desenvolvimento moral feminino é expresso pelo tendencioso parâmetro utilizado por Kohlberg ${ }^{20}$ na determinação dos estágios de raciocí- 
nio moral, que priorizou o sentido de justiça e do respeito às regras sociais em detrimento das relações interpessoais.

Assim, a supervalorização do pensamento masculino no campo da filosofia e da ética conduz a discussão da moralidade "em torno de questões de justiça, equidade, regras e direi$\operatorname{tos}^{\prime \prime 21}$ (p. 85), distanciando-se do pensamento feminino, que enfoca nas pessoas, "desejos, necessidades, interesses e aspirações" $^{21}$ (p. 85), numa perspectiva do cuidado.

Neste ponto, é importante evidenciar as distinções entre essas duas abordagens éticas, nas quais a justiça, de abordagem abstrata, assume a autonomia, se concentra na igualdade, possui aplicabilidade pública, sublinha o papel da razão que permite ações corretas e traduz o universo masculino; já o cuidado, de abordagem contextual, assume o relacionamento humano, centra-se na manutenção de relações, é aplicável no domínio privado, salienta o papel das emoções no bom caráter e é relativo ao gênero feminino ${ }^{22}$.

Em seu raciocínio moral, as "mulheres trazem ao ciclo da vida um diferente ponto de vista e organizam a experiência humana em termos de diferentes prioridades"11 (p. 22). Logo, "o ilusório mistério do desenvolvimento das mulheres reside no seu reconhecimento da permanente importância do apego na vida humana [...] o lugar da mulher na vida do homem é proteger esse reconhecimento enquanto a ladainha desenvolvimental canta a celebração da separação, autonomia, individuação e direitos naturais"11 (p. 23).

Gilligan $^{1}$, ao desenvolver um estudo das mulheres, extrai "constructos desenvolvimentais a partir de suas vidas, o esboço de uma concepção moral diferente da descrita por Freud, Piaget e Kohlberg"1 (p. 19), na qual "o problema moral surge de responsabilidades conflitantes e não de direitos em disputa, e exige [...] um modo de pensar que é contextual e narrativo em vez de formal e abstrato"1 (p. 19), que "centra o desenvolvimento moral em torno da compreensão da responsabilidade e dos relacionamentos ${ }^{\prime 1}$ (p. 19), distinto do desenvolvimento moral vinculado à "compreensão de direitos e regras"1 (p. 19).

Gilligan $^{23}$ identificou a ética do cuidado não exclusivamente caracterizada pelo gênero, mas como uma voz que verbaliza a razão, a emoção e parte da condição humana de que somos relacionais e interdependentes. Assim, a ética do cuidado é fundamentada nos relacionamentos, na importância de todos terem uma voz, sua lógica é indutiva (psicológica) e não dedutiva (matemática).

A ética do cuidado "reflete um conhecimento cumulativo dos relacionamentos humanos, progride em torno de uma visão central, de que o eu e o outro são interdependentes"11 (p. 74).

Noddings ${ }^{24}$, nessa mesma linha anti-hegemônica que nega a supervalorização do pensamento masculino frente ao pensamento feminino, desenvolve uma reflexão crítica em relação à ética kantiana, que "ignora a natureza e o papel dos sentimentos humanos, emoções e inclinações" ${ }^{\prime 25}$ (p. 3), estabelecendo os preceitos de uma ética não relacional e "que não apresenta responsabilidade para o crescimento moral" 25 (p. 4).

Para Noddings ${ }^{24}$, a ética deve, enfaticamente, ancorar-se em relações diretas, pautadas no cuidado, ou seja, uma ética do cuidado "característica e essencialmente feminina, o que não significa dizer, é claro, que ela não possa ser compartilhada pelos homens, da mesma forma que não poderíamos dizer que os sistemas morais não podem ser abraçados pelas mulheres"24 (p. 21).

Vale destacar que "Noddings defende a proposta de uma ética do cuidado em detrimento de uma ética de princípios, ao contrário do que é sugerido por Gilligan por meio da noção de complementaridade entre as duas vozes distintas da moral por ela identificadas [...] a feminina e a masculina"26 (p. 155).

Adotando como fundamentação a abordagem teórica sobre o desenvolvimento moral de Gilligan ${ }^{1}$ e Noddings ${ }^{24}$, o filósofo Michael Slote amplia essa perspectiva de abrangência da ética do cuidado, afirmando que "tem potencial para funcionar de forma compreensiva e satisfatória como uma verdadeira moralidade humana"2 (p. 8), ou seja, tem potencial para adquirir status de um projeto ético abrangente em relação à moralidade privada e pública. Assim, a proposta de Slote ${ }^{2}$ procura romper com o estigma que delimitou e cerceou a ética do cuidado como produto exclusivo de uma ética feminina.

Para este fim, Slote ${ }^{2}$ indica que a atitude ou a motivação ética solidária deve ser orientada pela empatia; utilizando o referencial teórico da psicologia e da filosofia, ele argumenta que a empatia é o principal mecanismo de cuidado, benevolência e compaixão. Assim, invoca o sentimentalismo na moral em ressonância com a filosofia contemporânea ao trabalhar a empatia.

A empatia "é a centelha de preocupação humana com os outros, a cola que torna a vida social possível [...] tem se sustentado por todo o período evolutivo e pode continuar enquanto existirem os seres humanos"33 (p. 3); é definida como "uma resposta afetiva mais adequada à situação do outro do que à própria situação"3 (p. 4), nos remete ao "estado de 'sintonia' emocional e cognitiva com outra pessoa, atingido, especificamente, através da compreensão da situação dessa outra pessoa a partir de dentro, ou seja, do que essa situação significa para ela"27 (p. 114-115), que, por sua vez, pode ou não preceder a simpatia, que, em um nível mais amplo, é a "capacidade de partilhar os sentimentos e interesses de outra pessoa com essa pessoa, acompanhando-a no prazer de suas alegrias e na dor de seus desgostos"'27 (p. 361).

Apesar de, teoricamente, tais conceitos induzirem a pensar numa ética da virtude, $S_{\text {lote }}^{2}$ nega que este seja o propósito 
da ética do cuidado orientado pela empatia. Ele aponta que a empatia é um elemento da percepção moral que orienta nossas atitudes; sendo assim, um ato é moralmente correto se não negligencia o cuidado, seja com atitudes voltadas às pessoas próximas ou distantes e pessoalmente desconhecidas.

Slote $^{2}$ reconhece que elementos como a distância e o imediatismo moldam nosso julgamento moral e nossas atitudes, o que revela um sentido hierarquizado das relações que germinam do desenvolvimento natural da empatia humana. Assim, a ética do cuidado antepõe os mais próximos, devido à empatia que se estabelece desde o grau mais próximo de parentesco, amizade, pertencimento a grupos, em ordem decrescente de prioridade (quanto mais distante, menor empatia), ao contrário da ética de justiça, que procura um agir imparcial.

Sendo assim, o comprometimento humano que emerge da relação com o outro tende à parcialidade, visto que é mais intuitivo e até instintivo compartilhar sentimentos com as pessoas mais próximas a nós. Tal dinâmica passa a ser imperiosa especialmente se houver situações imediatas que exigem nossa intervenção.

Embora a distância espacial possa justificar a intuição moral comum ou a escolha de uma conduta que privilegie os mais próximos ${ }^{28}$, a empatia pode representar uma base mais forte para distinguir nossas obrigações, visto que, de acordo com a ética do cuidado, um individuo idealmente virtuoso também estará preocupado com os distantes ${ }^{2}$.

Slote $^{2}$ indica ser possível desenvolver a empatia, criar e manter cuidado/preocupação com os outros. Assim, a educação moral pode conduzir-nos a uma preocupação empática pela pessoa ou grupos de pessoas que não conhecemos muito bem ou que em absoluto não conhecemos.

Devido à capacidade humana para representar eventos e imaginar-se no lugar do outro, e devido ao poder dos eventos representados para evocar afetos, para sentir uma angústia empática precisamos apenas imaginar as vítimas, como quando lendo sobre o infortúnio de alguém, discutindo sobre economia ou questões políticas que envolvem vítimas ou potenciais vítimas, ou até mesmo fazendo juízos ao estilo de Kohlberg sobre dilemas morais hipotéticos [...] assim, a capacidade de representar expande a importância da moralidade empática para além dos encontros face a face ${ }^{3}$ (p. 8).

Segundo Hoffman ${ }^{29}$, como resultado de uma educação moral, o indivíduo pode desenvolver empatia com os distantes geograficamente (pessoas ou populações) ou temporalmente (futuras gerações), aplicando em tais casos os mesmos julgamen- tos morais atribuídos aos que estão mais próximos; essa mesma lógica empática pode ser aplicada em relação aos animais.

Cabe ressaltar que, como parte de um projeto ético abrangente, o desenvolvimento da preocupação empática com os distantes se distingue do pragmatismo e da exigência da obrigação de ajudar os outros. Por um lado, Singer ${ }^{30}$ excede os limites da obrigação moral comum, mencionando que a distância não pode ser moralmente relevante para as nossas obrigações de ajudar as outras pessoas, ou seja, a nossa obrigação de ajudar uma pessoa próxima é a mesma de ajudar uma pessoa distante em situação limite comparável; por outro lado, Slote ${ }^{2}$ contesta essa imposição, evidenciando os razoáveis limites da obrigação moral, onde uma pessoa tem a obrigação de ajudar o outro distante sempre que possível, desde que não produza novos danos ou negue sua intuição moral (intuição empática), visto que, ao permitir que algo aconteça a uma pessoa próxima para ajudar outra distante, poderia gerar um dano moral e até psicológico para si mesma.

Embora a hierarquização das relações remeta a um cuidado como um sentimento particular, não nega a importância da promoção de relações solidárias públicas. Para Slote², podemos promover a justiça social ao ampliar o emprego da empatia a um nível institucional e legal, estabelecendo uma dinâmica entre as esferas privada e pública, traduzindo com maior sensibilidade o caráter de nossas intuições morais sobre a justiça.

Ao falarmos de justiça, elevamos a amplitude da empatia a um nível político, o que exige que determinadas regras sejam um divisor comum na vida em sociedade. Neste sentido, uma lei será mais justa "se ela refletir ou expressar empaticamente motivação para o cuidado de seus compatriotas, por parte do grupo legislativo que é responsável por aprová-la"² (p. 95). Há, portanto, uma contribuição deontológica para a ética do cuidado, enquanto a mesma produz uma crítica significativa, ou uma via alternativa ao utilitarismo, oferecendo vantagens intuitivas em relação a um racionalismo moral hegemônico.

A justiça regida pelas instituições é essencial para o controle da sociedade. Contudo, tende a omitir-se da realidade das pessoas, uma vez que, embora todos sejam iguais perante a lei, suas necessidades e desejos não são iguais. Deste modo, havendo diversidade de necessidades entre as pessoas, as oportunidades também não devem ser iguais numa população socialmente e economicamente desigual ${ }^{31}$.

Assim, a equidade "opera como um critério básico de orientação hermenêutica, atendendo à 'natureza, das coisas' e, mais especificamente, à particularidade de cada caso"32 (p. 12). Deste modo, "a natureza do equitativo é uma correção da lei quando esta é deficiente em razão da sua universalidade" ${ }^{\prime 33}$ (p. 116), já que "não é possível fazer uma afirmação universal que 
seja correta em relação a certos casos particulares" ${ }^{\prime 33}$ (p. 115); ou seja, "enquanto a justiça em si é medida abstrata, suscetível de aplicação a todas as hipóteses a que se refere, a equidade já é a justiça no seu dinâmico ajustamento ao caso"34 (p. 123).

Neste sentido, há certa congruência entre equidade e empatia $^{3}$. Enquanto a ética de justiça procura um agir imparcial, adotando uma perspectiva coletiva e abstrata, pautada na lei, não garantindo de modo eficiente a equidade, a ética do cuidado pela empatia procura um agir relacional, acessando com maior eficiência as singularidades, as vulnerabilidades e as inequidades, e, de certo modo, contribuindo para a equidade, numa perspectiva concreta, seja individual ou direcionada a grupos. Portanto, a ética do cuidado pela empatia "enfatiza a conexão com os outros, tanto no que diz respeito à base normativa da moralidade quanto em relação aos caminhos pelos quais a bondade moral se mostra dentro de uma vida moralmente boa" 35 (p. 12). Assim, "princípios morais podem ser ativados quando há empatia com pessoas ou grupos em situações de desvantagem"29 (p. 75).

Enquanto a "ética de justiça e direitos nos diz para regularmos as nossas ações ou vidas de acordo com certos princípios morais gerais, [...] a ética do cuidado salienta o bem de uma preocupação com o bem-estar dos outros, que não é mediada por princípios, regras, ou julgamentos" ${ }^{\prime 35}$ (p. 11); na ética do cuidado, "o ato de cuidar é tratado como uma virtude natural [...] nos envolve em conexão com outras pessoas [...] sem ter que invocar ou ser guiado por princípios morais explí$\operatorname{citos}^{\prime 35}$ (p. 11), o que permite melhor conexão com os "outros do que alguém que age apenas com base em tais princípios de mediação" ${ }^{\prime 35}$ (p. 12).

Deste modo, a "empatia pode desempenhar um papel importante no julgamento moral"3 (p. 16), assim como quando incorporada em um princípio moral, já que a "concorrência entre um afeto empático e um princípio moral permite criar um vínculo entre eles [...] deste modo, princípios morais podem adquirir propriedades afetivas e motivadoras de empatia e podem se tornar representações carregadas de emoção ou pró-sociais" $^{\prime 3}$ (p. 15).

\section{O CUIDADO ÉTICO}

O cuidado é parte de toda a ética,

integra, antes de mais, o sentido do próprio existir humano. Cuidamos "naturalmente" de nós e dos outros, pelo simples fato de existirmos-com-o(s)outro(s)-no-mundo. É por isso que criamos, a partir daí, contextos específicos destinados à sua valorização através de procedimentos "técnicos" concretos. Contudo, e a seu modo, todo o ser humano possui a capacidade do cuidado e/ou do cuidar. Do mesmo modo, todo ser humano, independentemente das suas diferenças e da sua singularidade própria, é um ser ético ${ }^{36}$ (p. 485).

O cuidado, no latim cura, emana da própria natureza humana, tal como enunciado na Fábula de Higino: "como, porém, foi a 'cura' [cuidado] quem primeiro o formou, ele [ser humano] deve pertencer à 'cura' enquanto viver"s (p. 264). Este foi um dos pontos de partida da reflexão de Heidegger ${ }^{8}$ sobre o cuidado na obra Ser e tempo, onde o cuidado é apresentado como a totalidade existencial de toda estrutura ontológica do ser-aí, que representa não apenas a presença, mas também o ato e o modo de se manifestar enquanto ser-no-mundo, que, por sua vez, é a consciência, o compreender, o revelar-se no mundo.

Assim, escreve Sêneca em sua última carta (Ep. 124): “[...] na perfeição de um, a saber, de Deus, o bem realiza sua natureza e na perfeição do outro, do homem, a cura: unius bonum natura perficit, dei scilicet, alterius cura, hominis [...]. Burdach chama a atenção para um duplo sentido do termo "cura", em que ele não significa apenas um "esforço angustiado", mas também o "cuidado" e a "dedicação"8 (p. 264-265).

O cuidado dasein, do ser-aí sendo ser-no-mundo, manifesta-se também como ser-com-os-outros, onde "o outro vem ao encontro em sua copresença no mundo"s (p. 171).

O dasein comporta três dimensões do cuidado, que indicam distintas intencionalidades: sorge expressa o cuidado de si, fürsorge expressa o cuidado de alguém, e besorgen expressa o cuidado de algo 8 .

Assim, o reconhecimento ético da vida humana, do si-com-o-outro (ser-com-os-outros) e do si-mesmo-como-outro (ser-aí ou ser-no-mundo) implica uma atitude de cuidado (respectivamente, fürsorge e sorge) e de responsabilidade ${ }^{37}$.

A responsabilidade "é uma obrigação de fazer que extrapola o âmbito da reparação e da punição. Essa extrapolação é tão insistente, que é com esse significado que o termo se impõe hoje em filosofia moral, a ponto de ocupar todo o terreno e de tornar-se 'princípio' em Jonas e, em grande parte, em Lévinas" $^{\prime \prime 38}$ (p. 34).

De acordo com Jonas ${ }^{13}$, o cuidado é o fundamento essencial para o desenvolvimento da vida e para a garantia da sobrevivência humana, remete a cuidar das gerações futuras, trata-se de uma "responsabilidade ôntica (ou "responsabilidade para com o ser")" ${ }^{\prime \prime 39}$ (p. 953), ou seja, expressa "o dever de responsabilidade com a totalidade do $\operatorname{ser}^{2 \prime 39}$ (p. 952).

Para Lévinas ${ }^{10}$ (p. 168), "não sou sem responsabilidade", a responsabilidade é compreendida "como responsabilidade por outrem, portanto, como responsabilidade por aquilo que 
não fui eu que fiz ou não me diz respeito; ou que precisamente me diz respeito, é por mim abordado como rosto" ${ }^{\prime \prime 9}$ (p. 87); assim, remete a cuidar do outro, trata-se de uma "responsabilidade diacônica (ou "responsabilidade para com o outro")"39 (p. 953).

O cuidado é, portanto, o exercício da responsabilidade; esta, por sua vez, "na ética significa assumir o controle do que se realiza frente ao afetado [vulnerado], corolário do qual pode ser o cuidado de outro ser humano quando este está ameaçado em sua vulnerabilidade ${ }^{\prime \prime 39}$ (p. 951).

Tanto Jonas ${ }^{13}$ no cuidado para com as gerações futuras, quanto Lévinas ${ }^{10}$ no cuidado com o outro, acentuam a responsabilidade frente à vulnerabilidade. Assim, "responsabilidade ôntica e responsabilidade diacônica têm características comuns: não são fruto de uma solicitude explícita, mas da vulnerabilidade do sujeito que sugere a necessidade de proteção que é oferecida pelo agente moral" ${ }^{\prime 39}$ (p. 953).

A existência humana "tem o caráter precário, vulnerável e revogável, o modo peculiar de transitoriedade da vida, o que a torna um objeto próprio de cuidado"12 (p. 98). Deste modo, a vulnerabilidade "é a obsessão pelo outro ou a aproximação do outro [...] sofrer pelo outro é tê-lo ao cuidado, suportá-lo, estar em seu lugar, consumir-se por ele [...] o sujeito é para o outro: substituição, responsabilidade" ${ }^{\prime 11}$ (p. 124-125).

A vulnerabilidade exige cuidados ${ }^{13}$, e assim, no campo da saúde, o cuidado envolve toda a relação interpessoal, ou "intersubjetiva"10 (p. 184), entre um protetor e um necessitado de proteção (vulnerado/afetado).

Nesse sentido, é estabelecido um pacto de cuidados que "implica uma relação com o outro [paciente] sobre a figura do médico assistente, mas no interior de uma instituição de base, a profissão médica"14 (p. 19), e que se assenta na confiança, "de um lado aquele que sabe e sabe fazer, do outro aquele que sofre"14 (p. 6).

Heidegger aponta muito positivamente para o fato de que se o ser do humano é um estar lançado no mundo, numa reconstrução constante de si mesmo e desse mundo, elucidada pela ideia de Cuidado, será justo assumir que as práticas de saúde, como parte desse estar lançado, tanto quanto dos movimentos que o reconstroem, também se elucidam como Cuidado. Também no plano operativo das práticas de saúde é possível designar por Cuidado uma atitude terapêutica que busque ativamente seu sentido existencial ${ }^{40}$ (p. 22).

A atitude terapêutica comporta uma dimensão prática "da ordem do cuidar e do curar ${ }^{\prime \prime 14}$ (p. 3), suscitando questões éticas, na medida em que diz "respeito a intervenções deliberadas no processo da vida humana"14 (p. 3), ou seja, suscita juízos prudenciais e deontológicos. Os juízos prudenciais são aplicados "em situações singulares nas quais um paciente individual é colocado numa relação interpessoal com um médico individual"14 (p. 4), expressando "uma sabedoria prática de natureza mais ou menos intuitiva resultante do ensino e do exercício"14 (p. 4); por sua vez, os juízos deontológicos são orientados pelo código profissional "na medida em que juízos revestem a função de normas que transcendem de diferentes formas a singularidade da relação entre um certo paciente e um certo médico"14 (p. 4).

É no encontro com o outro que se expressa o cuidado em saúde, partindo da premissa de que esse outro o reconheça como tal. Para que haja o reconhecimento do cuidado em saúde, deve-se "constituir um agir cumpliciado do trabalhador com a vida individual e coletiva"41 (p. 69). Neste sentido, o acolhimento e o vínculo se consubstanciam em elementos fundamentais no "espaço intercessor" ${ }^{\text {"41 }}$ (p. 26) - onde se produz o "trabalho vivo [autônomo, criativo, não cristalizado, instituinte] em ato [produção e consumo, simultaneamente, do cuidado] ${ }^{\prime \prime 11}$ (p. 19) - que se estabelece no encontro entre os profissionais e os pacientes que buscam "relações de confiança, a certeza de que seu problema vai ser entendido, e o compromisso de que tudo que puder ser feito para defender e qualificar a sua vida será objeto das ações dos profissionais" ${ }^{\prime 11}$ (p. 75).

Quando o cuidado é plenamente reconhecido, permite a construção da autonomia do paciente em relação à sua própria saúde. Esse seria, portanto, um cuidado ético que procura de fato a resolutividade dos problemas que determinam e condicionam o processo de adoecimento, que vão além dos aspectos puramente biológicos.

Essa "ação produtiva é duplamente transformadora, onde ao mesmo tempo em que o trabalhador produz os atos de cuidado, mudando a realidade, produz a si mesmo como sujeito"41 (p. 196).

A ação produtiva do cuidado ocorre na micropolítica do trabalho, onde observamos um "dinâmico e complexo modo operativo de cada trabalhador na sua ação cotidiana, inclusive sua produção subjetiva em ato, que produz o cuidado em saúde, e, ao mesmo tempo, produz o próprio trabalhador enquanto sujeito no mundo"41 (p. 152); isto é, na micropolítica encontramos um grande potencial transformador, por representar um espaço de intersubjetividade sensível ao dinamismo das produções em ato na saúde, "na qual somos individual e coletivamente fabricadores e fabricados nos nossos modos de agir e nos nossos processos relacionais" ${ }^{\prime 41}$ (p. 340).

Nesta orientação, o trabalhador opera em uma dupla lógica, "a de ser trabalhador dotado de plena capacidade técnica de intervir sobre problemas de saúde, e opera também uma 
dimensão subjetiva, a de ser para si e o outro, conferindo alteridade nos atos de cuidado, onde o outro está sempre presente como sujeito na ação de produzir o cuidado"41 (p. 188).

Contudo, tanto o compromisso médico como a própria dimensão subjetiva podem ser comprometidos pela "intrusão quer das ciências biomédicas que tendem para a objetivação e reificação do corpo humano, quer da intrusão da problemática da saúde pública, que se prende com o aspecto não mais individual, mas coletivo, do fenômeno geral da

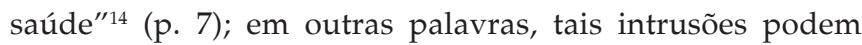
gerar a captura e a cristalização do trabalho vivo, seja pelo tecnicismo ou pelo cientificismo, e a perda da dimensão subjetiva do cuidado ${ }^{41}$.

Entretanto, "apesar do avanço da tecnologia médica, uma relação positiva entre médicos e pacientes continua a ser essencial para um cuidado de qualidade"7 (p. 1100), considerando que a "medicina é uma das práticas baseadas numa relação social para a qual o sofrimento é a motivação fundamental e o telos [finalidade] é a esperança de obter ajuda e talvez ser curado [...] tem como foco a saúde física e mental"14 (p. 5)

A saúde, como um bem-estar físico, mental e social, é a orientação máxima da qualidade de vida, que expressa a responsabilidade do governo e dos profissionais da saúde pelo cuidado e acentua a importância de que os processos de educação permanente e de formação superior em saúde incorporem no ensino a humanização das práticas médicas e o desenvolvimento de habilidades empáticas, permitindo que o profissional/aluno lance um olhar integral, equânime e singular ao paciente, rompendo, assim, com a prática fragmentada que tem orientado o modelo biomédico hegemônico, que tem, entre outros fatores, desconsiderado aspectos psicossociais essenciais à promoção e à garantia de saúde.

A "medicina centrada no paciente tem suas raízes no paradigma do holismo, o que sugere que cada pessoa tem a necessidade de ser entendida como um todo biopsicossocial" ${ }^{\prime 2}$ (p. 527).

Entre os preceitos da prática médica há "o reconhecimento do caráter singular da situação de cuidados [...] esta singularidade implica o caráter insubstituível de uma pessoa em relação a outra"14 (p. 8) e a "indivisibilidade da pessoa; não são múltiplos órgãos que são tratados, mas um doente integral"14 (p. 8); esses preceitos se opõem ao "gênero de clivagem entre o biológico, o psicológico e o social"14 (p. 8).

Estudantes da área médica "podem se beneficiar da formação regular de longo prazo que inclui esforços conscientes para desenvolver suas habilidades empáticas [...] isto é valioso para ambos, médicos e pacientes, para enfrentar o mundo cada vez mais fragmentado e tecnológico da medicina moderna"7 (p. 1100).
A incorporação dessa perspectiva do cuidar na prática profissional exige uma nova lógica do ensino superior, que permita "realizar a mudança de um modelo de atenção corporativo centrado para um usuário centrado" ${ }^{41}$ (p. 69), formando profissionais comprometidos "com a tarefa de acolher, responsabilizar, resolver, autonomizar"41 (p. 77).

Deste modo, o processo de formação profissional é um elemento estratégico na consolidação do novo paradigma da saúde pública brasileira, inaugurado com o advento do Sistema Único de Saúde. Entretanto, é fato que o sistema de educação superior, especialmente no campo da saúde, não acompanhou, de modo articulado, o processo de reforma sanitária.

Para superar esta desarticulação, surgiram, com a reforma curricular, as novas Diretrizes Curriculares dos Cursos de Graduação em Saúde, a exemplo do curso de Medicina, que procurou instituir a "formação generalista, humanista, crítica e reflexiva [...] pautada em princípios éticos, [...] com senso de responsabilidade social e compromisso com a cidadania, como promotor da saúde integral do ser humano" ${ }^{43}$ (p. 1), promovendo “a interação ativa do aluno com usuários e profissionais de saúde desde o início de sua formação, proporcionando ao aluno lidar com problemas reais, assumindo responsabilidades crescentes como agente prestador de cuidados e atenção" 43 (p. 5), para que os futuros profissionais realizem "seus serviços dentro dos mais altos padrões de qualidade e dos princípios da ética/bioética, tendo em conta que a responsabilidade da atenção à saúde não se encerra com o ato técnico, mas, sim, com a resolução do problema de saúde, tanto a nível individual como coletivo" 43 (p. 1).

Considera-se, assim, que o aluno "em sua socialização profissional não é um mero objeto a ser moldado conforme as vontades e preceitos da sua futura corporação, mas também sujeito ativo desse processo, isto é, ator"44 (p. 59).

Esse processo de socialização profissional, na perspectiva de um desenvolvimento moral, oferece ao aluno de cursos de formação na área da saúde uma "interiorização de submundos, ou subculturas específicas, diretamente relacionadas à complexidade da divisão do trabalho"44 (p. 52); é habitual que, nessa interação, "múltiplos e díspares agentes de socialização interajam com o indivíduo"44 (p. 52), em um processo onde "a empatia e a compaixão são fatores terapêuticos importantes para pacientes com doenças físicas" ${ }^{\prime 4}$ (p. 174).

Deste modo, "a empatia pode enriquecer a prática médica, pode-se cogitar a possibilidade de ensinar a ser empático ou discutir a importância da empatia sob a ótica de docentes do curso de Medicina"46 (p. 261).

Cabe ressaltar que o desenvolvimento da empatia e a valorização de "tecnologias leves"41 (p. 100) ou relacionais são 
um desafio na prática médica, que ainda recebe forte influência do modelo biomédico biologizante, mas cabe salientar que "a empatia pode ser melhorada e ensinada com sucesso na escola médica, especialmente se ela for incorporada em experiências reais dos alunos com os pacientes" ${ }^{47}$ (p. S9). Embora a empatia seja desejável em todos os níveis de atenção, evidências na literatura sugerem que "o ensino da empatia desempenha um papel fundamental na resolutividade da atenção primária em saúde ${ }^{\prime 47}$ (p. S9), devido às características desse modelo de atenção, como, por exemplo, o acompanhamento longitudinal (ao longo do tempo, contribuindo para a criação de vínculo) e a maior possibilidade do emprego de tecnologias leves no encontro entre o profissional e o paciente, que favorecem o desenvolvimento de habilidades empáticas, por parte tanto dos profissionais quanto dos alunos que participam dos estágios extramuros, evidenciando "correlações positivas com a melhoria da formação de profissionais de saúde" ${ }^{\prime 6}$ (p. 268).

Não se pode olvidar que "as técnicas nunca podem ser empregadas em um contexto livre de significado interpessoal"45 (p. 177), visto que o ato de cuidar é "inviável sem o sentimento de empatia, que também é um dos atributos essenciais na relação médico-paciente e qualquer outra relação profissional na saúde em que se pense o cuidado como uma responsabilidade ética e moral do outro em um momento de fragilidade emocional e física"48 (p. 309).

Considera-se que "tanto a competência técnica quanto as características pessoais - como empatia e compromisso/responsabilidade - são importantes para a satisfação [e cuidado] do paciente" ${ }^{\prime 49}$ (p. 25), pois permitem, na relação terapêutica, “iniciar uma comunicação de apoio, interpessoal, a fim de compreender as percepções e necessidades do paciente [...] habilita o paciente a aprender, ou lidar mais eficazmente com o seu meio ambiente; e a redução ou resolução de problemas de saúde" ${ }^{\prime 47}$ (p. S10).

Neste sentido, formar profissionais humanizados e sensibilizados com as singularidades dos indivíduos que necessitam de cuidados exige o emprego de estratégias que permitam um processo de desenvolvimento moral que privilegie o desenvolvimento da empatia aproximando o aluno da complexa realidade social. É o que têm proposto os estágios extramuros ao responderem às insuficiências da capacitação técnica e da transmissão objetiva de conhecimentos do modelo de formação tradicional, que, em grande parte, tem ignorado o potencial subjetivo tanto dos estudantes quanto de seus futuros pacientes.

Essa ideia concreta de educação moral, na formação médica, visa "converter-se em um âmbito de reflexão individual e coletiva que permita elaborar racional e autonomamente princípios gerais de valor, princípios que ajudem a defrontar- -se criticamente com realidades" ${ }^{\prime 50}$ (p. 15), contribuindo para a construção de "hábitos de convivência que reforcem valores como a justiça, a solidariedade, a cooperação ou o cuidado com os demais" ${ }^{\prime \prime 0}$ (p. 15).

De fato, a aproximação dos alunos com a rede de atenção à saúde, especialmente no âmbito da atenção primária, permite um contato mais próximo com a realidade e com os usuários do sistema. Tal dinâmica contribui para a ressignificação do processo de formação de modo ativo, com a participação ativa do aluno, e para o desenvolvimento de empatia em relação ao paciente e ao sistema público (da esfera privada para a pública), contribuindo para a formação de profissionais humanistas e sensíveis às reais necessidades dos cidadãos, em uma lógica transdisciplinar e multiprofissional, desenvolvendo o senso de compromisso, responsabilidade e cuidado ético.

\section{CONSIDERAÇÕES FINAIS: A ÉTICA DO CUIDADO PELA EMPATIA}

A ética do cuidado surgiu em resposta aos diversos olhares, vozes e outros sentidos que materializaram e perpetuaram a "violência simbólica"19 (p. 12) do masculino sobre o feminino na sociedade. Na verdade, tal violência se materializa na opressão estrutural da sociedade do homem contra a mulher em diversos campos do pensamento, uma vez que foram e ainda são produzidas, com base nesse binômio, hierarquias concretas que privilegiam tudo aquilo que promove a valorização do universo masculinista.

Assim, numa tentativa de repensar e questionar esta construção histórica de que o desenvolvimento moral do homem (masculino) atingia estágios superiores aos da mulher (feminino), Gilligan ${ }^{1}$ apresenta a ética do cuidado como uma voz diferente, caracterizada não exclusivamente pelo gênero, que parte da condição de que somos seres relacionais e interdependentes. Nessa direção, a autora propõe uma ética que não reinventa ou inverte as hierarquias, mas complementa a ética de justiça.

Evidentemente, houve e ainda há divergências teóricas sobre como podemos pensar a moralidade a partir do binômio feminino/masculino. De toda maneira, é por meio dos estudos de Gilligan ${ }^{1}$ que este campo passa a debater tais questões, considerando: (1) a influência da construção social na distribuição e restrição da vida privada e pública; (2) a influência da perspectiva naturalista da psicologia evolucionista. Diante disso, Gilligan" (p. 23) destaca que "somente quando os teóricos da vida dividirem sua atenção e começarem a viver com mulheres do modo como têm elas vivido com os homens, sua visão abrangerá a experiência de ambos os sexos e suas teorias se tornarão, portanto, mais férteis". 
Nesta mesma direção, ao propor a universalização da ética do cuidado pela empatia, Slote ${ }^{2}$ abre um caminho para ampliar as discussões sobre a construção de uma moral que rompa com um tipo de pensamento masculinista centrado e, simultaneamente, procura dissociar a ética do cuidado da chamada percepção exclusivamente feminina, procurando, assim, um equilíbrio entre as distintas vozes, aqui apresentadas na situação entre a justiça e o cuidado.

Deste modo, Slote ${ }^{2}$ propõe desenvolver um projeto ético abrangente em relação à moralidade privada e pública, elevando a ética do cuidado a um status universal e invertendo a lógica do desenvolvimento moral que supervaloriza a justiça, passando a evidenciar o estágio relacional como norteador do agir ético, por meio da empatia.

Tal perspectiva procura romper com a abordagem abstrata e imparcial, que sublinha o papel da razão, sem negar a deontologia, visto que são necessárias regras comuns para se viver em sociedade. Essa abordagem tampouco ignora a justiça social, uma vez que o conceito de empatia visa abranger o nível institucional e legal, traduzindo com maior sensibilidade o caráter das nossas intuições morais sobre a justiça.

No campo da saúde, a ética do cuidado teria o papel de encaminhar essa perspectiva à ressignificação das práticas por meio da relação interpessoal, do "ser-com-os-outros"8 (p. 170), uma vez que prioriza a confiança, autonomia, corresponsabilidade, resolutividade, reconhecimento e vínculo. O cuidado, quando reconhecido, permitiria, por meio da empatia, desenvolver as ações de saúde no campo da sensibilização recíproca, entre o profissional e o usuário, contribuindo para o reconhecimento das singularidades e para a conquista da equidade. Isso faz com que haja um distanciamento de uma abordagem que prioriza a imparcialidade ou a impessoalidade, elementos geralmente relacionados à concepção moral da justiça, que tende a desconsiderar, sensivelmente, as condições necessárias para que se conquiste a igualdade em diversos níveis. Enfim, o cuidado empático seria, aqui, um caminho para garantir a equidade ao invés da promessa de uma igualdade abstrata incapaz de considerar, efetivamente, o outro em sua singularidade e complexidade.

O processo de formação de profissionais da saúde, por meio dos estágios ou disciplinas extramuros, tem sido um exemplo prático de uma ação que sinaliza e privilegia a importância da empatia no campo das relações de cuidado. Tal importância já pode ser percebida pela aproximação dos alunos com os usuários do sistema de saúde, em um movimento de sensibilização mútua, capaz de ressignificar para ambos o sentido de um cuidado ético que possibilite maior resolutividade e autonomização em saúde.

\section{REFERÊNCIAS}

1. Gilligan C. In a different voice: psychological theory and women's development. Cambridge: Harvard University Press; 2003.

2. Slote M. The ethics of care and empathy. New York: Routledge; 2007.

3. Hoffman ML. Empathy and moral development: implications for caring and justice. New York: Cambridge University Press; 2000.

4. Hoffman ML. Empathy, role-taking, guilt, and development of altruistic motives. Michigan: University of Michigan; 1973.

5. Flavell JH. Role-taking and communication skills in children. Young Child. 1966; 21(3)164-177.

6. Rogers CR. The necessary and sufficient conditions of therapeutic personality change. J. Consult. Psychol. 1957; 21(2):95-103

7. Larson EB, Yao X. Clinical empathy as emotional labor in the patient-physician relationship. JAMA 2005; 293(9):1100-1106.

8. Heidegger M. Ser e tempo I. Petrópolis: Vozes; 2005.

9. Lévinas E. Ética e infinito. Lisboa: Edições 70, 1988.

10. Lévinas E. O tempo e o outro. Rev. Phainomenon 2005; 11:149-190.

11. Lévinas E. Humanismo del otro hombre. México: Siglo XXI Editores; 2009.

12. Jonas $\mathrm{H}$. The imperative of responsibility: in search of an ethics for the technological age. Chicago: University of Chicago Press; 1985

13. Jonas H. O princípio responsabilidade: ensaio de uma ética para a civilização tecnológica. Rio de Janeiro: Contraponto/PUC Rio; 2006.

14. Ricoeur P. Os três níveis do juízo médico. Covilhã: LusoSofia; 2010

15. Aristóteles. Política. São Paulo: Martin Claret; 2007.

16. Kant I. A metafísica dos costumes. Bauru: EDIPRO; 2003.

17. Freud S. Obras completas, volume 16: o eu e o id, "autobiografia" e outros textos (1923-1925). São Paulo: Companhia das Letras; 2011.

18. Rachels J. Elementos de filosofia moral. Lisboa: Gradiva; 2004.

19. Bourdieu P. A dominação masculina: a condição feminina e a violência simbólica. Rio de Janeiro: BestBolso; 2014.

20. Bataglia PUR, Morais A, Lepre RM. A teoria de Kohlberg sobre o desenvolvimento do raciocínio moral e os instrumentos de avaliação de juízo e competência moral em uso no Brasil. Estud. psicol. (Natal) 2010; 15(1):25-32.

21. Tong R. Feminine and feminist ethics. Stanford: Wadsworth Publishing Company; 1993. 
22. Houser R, Wilczenski F, Ham M. Culturally relevant ethical decision-making in counseling. Thousand Oaks: SAGE Publications; 2006.

23. Gilligan C. Carol Gilligan: a ética do cuidado. University of Humanistic Studies [on line]. 2011. [capturado 29 mar. 2014]. Disponível em: http://ethicsofcare.org/interviews/carol-gilligan/.

24. Noddings N. O cuidado: uma abordagem feminina à ética e à educação moral. São Leopoldo: Unisinos; 2003.

25. Wike VS. Defending Kant against Noddings' care ethics critique. Loyola University [on line]. 2011. [capturado 02 jun. 2014]; 1-26. Disponível em: http://www.kantstudiesonline.net/.

26. Kuhnen TA. A ética do cuidado como alternativa à ética de princípios: divergências entre Carol Gilligan e Nel Noddings. Ethic@ 2010; 9(3):155-168.

27. Blackburn S. Dicionário oxford de filosofia. Rio de Janeiro: Zahar; 1997.

28. Kamm FM. Intricate ethics: rights, responsibilities, and permissible harm. Oxford: Oxford University Press; 2007.

29. Hoffman ML. The contribution of empathy to justice and moral judgment. In: Eisenberg N, Strayer J, orgs. Empathy and its development. New York: Cambridge University Press; 1987. p.47-80.

30. Singer P. Famine, affluence and morality. Phil. \& pub. aff. 1972; 1(3):229-243.

31. Sen A. A ideia de justiça. São Paulo: Companhia das Letras; 2011.

32. Reale M. A equidade no direito do trabalho. Rev. fac. dir. (USP) 1974; LXIX(1):09-17.

33. Aristóteles. Ética a Nicômaco. São Paulo: Martin Claret; 2013.

34. Reale M. Lições preliminares de direito. São Paulo: Saraiva; 2002.

35. Slote M. Justice as a virtue. Stanford Encyclopedia of Philosophy [on line]. 2014. [capturado 29 set. 2015]; 1-18. Disponível em: http:/ / plato.stanford.edu/entries/justice-virtue/.

36. Perdigão AC. A ética do cuidado na intervenção comunitária e social: os pressupostos filosóficos. Análise psicológica 2003; 4(XXI):485-497.

37. Ricoeur P. O si-mesmo como outro. São Paulo: Martins Fontes; 2014

38. Ricoeur P. O Justo I. São Paulo: Martins Fontes; 2008.

39. Schramm FR, Kottow M. Principios bioéticos en salud pública: limitaciones y propuestas. Cad. saúde pública 2001; 17(4):949-956.

40. Ayres JRCM. O cuidado, os modos de ser (do) humano e as práticas de saúde. Saúde soc. 2004; 13(3):16-29.
41. Franco TB, Merhy EE. Trabalho, produção do cuidado e subjetividade em saúde. São Paulo: Hucitec; 2013.

42. Macedo A, Cavadas LF, Sousa M, Pires P, Santos JA, Machado A. Empathy in family medicine. Rev. port. clin. geral 2011; 27:527-532.

43. Brasil. Ministério da Educação. Conselho Nacional de Educação. Câmara de Educação Superior. Resolução CNE/ CES nº 4 de 7 de novembro de 2001. Institui diretrizes curriculares nacionais do curso de graduação em Medicina. Diário Oficial da União. Brasília, 9 nov. 2001; Seção 1, p. 38.

44. Rego STA. A formação ética dos médicos: saindo da adolescência com a vida (dos outros) nas mãos. Rio de Janeiro: Editora Fiocruz; 2003.

45. Di Blasi Z, Kleijnen J. Context effects: powerful therapies or methodological bias? Eval. health prof. 2003; 26(2):166-179.

46. Costa FD, Azevedo RCS. Empatia, relação médico-paciente e formação em medicina: um olhar qualitativo. Rev. bras. educ. med. 2010; 34(2):261-269.

47. Mercer SW, Reynolds WJ. Empathy and quality of care. Br. J. Gen. pract. 2002; Quality Supplement:S9-S12.

48. Scholze AS, Duarte-Junior CF, Silva YF. Trabalho em saúde e a implantação do acolhimento na atenção primária à saúde: afeto, empatia ou alteridade? Interface - comunic., saúde, educ. 2009; 13(31):303-314.

49. Morinaga CV, Konno SN, Aisawa RK, Vieira JE, Martins MA. Frases que resumem os atributos da relação médico-paciente. Rev. bras. educ. med. 2002; 26(1):21-27.

50. Puig JM. Ética e valores: métodos para um ensino transversal. São Paulo: Casa do Psicólogo; 1998.

\section{CONTRIBUIÇÃO DOS AUTORES}

Marcelo de Almeida Mayernyik participou da concepção, revisão da literatura, discussão, redação e revisão do artigo. Fabio Alves Gomes de Oliveira participou da revisão da literatura, discussão, redação e revisão do artigo.

\section{CONFLITO DE INTERESSES}

Os autores declaram não haver conflito de interesses.

\section{ENDEREÇO PARA CORRESPONDÊNCIA}

Marcelo de Almeida Mayernyik

Universidade Federal Fluminense, Instituto de Saúde

Coletiva.

Rua Marquês de Paraná, 303, (Prédio Anexo ao Hospital

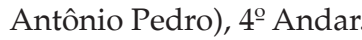

Centro - Niterói

CEP.: 24030210 - RJ

E-mail: mayernyik@yahoo.com.br 